\title{
Anti-Microbial and Antioxidant Activities of Ziziphus spina Christi, Sudanese Medicinal Plant
}

\author{
Mahdi Abdu-Almageed Mohamed Ali ${ }^{1}$, Asaad Alsiddig Ahmed ${ }^{2}$, Ali Abdurrahman Almakki ${ }^{3}$ and Hatim MY \\ Hamadnalla ${ }^{4 *}$ \\ ${ }^{1}$ Department of Biology and Technology, College of Applied Sciences - University of Bahri, Sudan \\ ${ }^{2}$ Department of Biology - Khartoum International Preparatory School, Sudan \\ ${ }^{3}$ Department of Microbiology, College of Applied Sciences- University of Bahri, Sudan \\ ${ }^{4}$ Department of Biochemistry, College of Applied Sciences, University of Bahri, Sudan \\ *Corresponding author: Hatim MY Hamadnalla, Department of Biochemistry, College of Applied Sciences, University of Bahri, Sudan
}

\begin{abstract}
This work is an anti-Microbial and Antioxidant activity of Ziziphus spina Christi based on four selected bacteria: Escherichia coli, Psedumonus aeruginosa, Bacillussubtilis and Staphylococcus aureus. These species were collected and prepared in Sudan. The concentrations were carried out and compared with standard control sample, the suspension of anti-microbial activities have shown different results in Fagonia cretica. The antioxidant activity is the ability of bioactive compounds to prevent, delay and protect against oxidant of virus substrates such as DNA and lipid materials, both in living organisms (e. g. human) and in food products. The result showed an antioxidant activity based on standard liquid reagent [1].
\end{abstract}

\section{Introduction}

Anti- Microbial is an agent that kills microorganisms such as bacterial or stops their growth. Anti-microbial medicines can be grouped according to the microorganisms they act primarily against. For example: antibiotics were used against bacteria and antifungals too [2]. Anti- Microbial can be further subdivided into bactericidal agent; instead, certain types of porous media have been developed to kill microbes on contact [3]. On the other hand, antioxidants are compounds that inhibit oxidation. This is a chemical reaction that can produce free radicals. Thereby, leading to chain reactions that may damage the cells of organisms. For example: thiols or ascorbic acid terminates these chain reactions. Mostly, antioxidants have two entirely different groups of substances: industrial chemical reactions which can be added to products and natural chemicals which can be presented in foods and tissues for resistant of cancer [4].Plant and animals maintain complex system of overlapping antioxidant [5].

\section{Study area}

The batch was found in west Om-Dorman region, Sudan. This area is mostly populated and features a hot arid climate routinely exceeded to $40{ }^{\circ} \mathrm{C}$ in midsummer, the region lay between $15.6476^{\circ}$ $\mathrm{N}, 32.4807^{\circ} \mathrm{E}$. This region considered as heliostat city of Sudan. The soil of this area is partly divided into two types: slab stone and muddy.

\section{Population}

According to ethno-botanical Omdurman area includes several people such as Arabs and Africans. Meanwhile, most of these people are officers beside other traditional works such as agriculture and animal husbandry.

\section{Methodology \\ Experimental materials}

Plant material was collected from west Om-Dorman region, Khartoum - Sudan in January 2020. The identification of the plant was carried out at natural research center and compared with herbarium of Department of Biology and Technology - Faculty of applied Science and industry - University of Bahri, Sudan. The medicinal plant was dried under dark shade for one week. 


\section{Preparation of crude extract}

One hundred gm. of whole plant material (Sedir - local name) was extracted by ethyl acetate for (24) hours at room temperature. The extracts were filtered using filter paper and air-dried. The final volume was adjusted to give the specific concentration. Yield of all extract was respected to dry starting materials.

\section{Anti-microbial activity (preparation of culture)}

Twenty-eight gm. of nutrient agar media was added to (1000) $\mathrm{ml}$. of distilled water. Seven gm. was added to (250) ml. distilled water on glass bottle volume (250) $\mathrm{ml}$. (4 bottles), the four bottles were shacked very well to dilute the powder media and (32.5) gm. of sabouraud dextrose agar was added to (500) ml. distilled water. Meanwhile, (16.25) gm. was added to (250) gm. distilled water on glass bottle volume (250) $\mathrm{ml}$. then all bottles were shacked and put on autoclave for sterilization at $\left(121^{\circ} \mathrm{C}\right)$ and $(15 \mathrm{Ibs})$ pressure for (15) minutes.

\section{Preparation of sabouraud}

Sixty two gm. of powdered sabouraud dextrose agar was weighted and dispersed in (1) liter of distilled water and allowed to soak for (10) minutes swirl to mixed and sterilized by autoclave for $(15)$ minutes at $\left(121^{\circ} \mathrm{C}\right)$ and cooled to $\left(47^{\circ} \mathrm{C}\right)$. Lastly, mixed well and poured into petri dishes.

\section{Bacteria organisms test}

a) Staphylococcus aureus (ATCC 6538 Gram +ve Bacteria).

b) Bacillus subtilis (ATCC 6633 Gram +ve Bacteria).

c) Psedumonus aeruginosa (ATCC 8739 Gram -ve Bacteria).

d) Escherichia coli (ATCC 8739 Gram -ve Bacteria).

\section{Preparation of organism's suspension}

One ml. aliquots of a (24) hours broth culture of the testing organisms were aseptically distributed on nutrient agar slopes and incubated at $\left(37^{\circ} \mathrm{C}\right)$ for $(24)$ hours, the bacteria growth was then harvested and washed off with (100) ml. sterile normal saline to produce a suspension containing a bout (108 - 109) C.F.U/ml., the suspension was then stored in a refrigerator at $\left(4{ }^{\circ} \mathrm{C}\right)$. The average number of organisms per ml. of the stock suspension was determined by the surface counting technique. (Miles and Misra, 1938).Serial dilutions of the stock suspension were made in sterile normal saline solution and (0.02) ml. volumes of the appropriate dilutions were transferred by micro-pipette onto the surface of dried nutrient agar plates, the plates were allowed to stand for (2) hours at room temperature with drops to dry and incubated at (37 ${ }^{\circ} \mathrm{C}$ ) for (2) hours, after incubation the number of developed colonies in each drop was counted. The average number of the colonies per drop of (0.02) ml. was multiplied by (50) and by dilution factor to give viable count of the stock suspension which expressed as a number of colony of the stock suspension which expressed as a number of colony forming unit (C.F.U). Therefore, each time of fresh stock suspension was prepared.

\section{Testing for anti-microbial activity}

The cup-plate agar diffusion method was adopted with some minor modifications to assess the anti-bacterial activity of the prepared extract [6]. One $\mathrm{ml}$. of standardized bacterial stock suspension 108 - 109 C.F.U/ml was thoroughly mixed with (100) $\mathrm{ml}$. of molten sterile nutrient agar which was maintained at $\left(45^{\circ} \mathrm{C}\right)$. Twenty ml. aliquots of inoculated nutrient agar were distributed into sterile petri-dishes, the agar was left to set in each of this four cup-plates (10 mm. in diameter) were cut using a sterile cork borer and agar was removed. Alternate cups were filtered with (0.1) $\mathrm{ml}$. sample of each of the oil dilutions in methanol using automatic micro-liter pipette at room temperature for (2) hours. The plates were then incubated in the upright position at $\left(37^{\circ} \mathrm{C}\right)$ for $(18)$ hours. Two replicates were carried out for each extract against each of the test organisms, after incubation the diameter of the resultant growth inhibition zones were measured, averaged and mean values were tabulated.

\section{DPPH radical scavenging assay}

The DPPH assay scavenging was determined according to the method of Shimada [1] with some modification. In 96-well plate, the test samples were allowed to react with 2,2-Di (4-tert-octyl phenyl)-1-picryl-hydrazyl stable free radical (DPPH) for half an hour at $37{ }^{\circ} \mathrm{C}$. The concentration of DPPH was kept as $(300 \mu \mathrm{M})$. The test samples were dissolved in DMSO while DPPH was prepared in ethanol. After incubation, decrease in absorbance was measured at $(517 \mathrm{~nm})$ using multiplate reader spectrophotometer. Percentage radical scavenging activity by samples was determined in comparison with a DMSO treated control group. All tests and analysis were run in triplicate.

\section{Discussion}

\section{Anti-Microbial}

Ethyl acetate solvent had been detected a precise output. The numbers of bacteria were infected by concentrations Table 1 . The dead bacteria were increased when we use anti-biotic. On other hand, P. aeruginosa and B. subtilis resulted the same dead bacteria against anti-biotic although they were different gram stains, while E. coli bacteria resulted the lowest number of dead bacteria. The (Table 1) also shows the increasing of concentrations have led to more infected bacteria. These results had been depended on the cell wall strengthen of the bacteria. The standard control samples had mentioned the numbers of colonies and the teared bacteria which were measured by (1) gm /ml. concentration. Several bioassay such as disk diffusion, well diffusion and broth or agar dilution are well known and commonly used, but others such as flow cytofluorometric and bioluminescent methods are not widely use because they requires specified equipment, evaluation for reproducibility and standardization [7]. 
Table 1: Anti-microbial activities of Ziziphus spina Christi plant against standard bacterial strains at concentration 1 gm/ml.

\begin{tabular}{|c|c|c|c|c|c|}
\hline \multicolumn{6}{|c|}{ Standard bacterial strains } \\
\hline \multirow{2}{*}{ Plant extract } & \multirow{2}{*}{ Concentrations } & E. coli & Paeruginosa & B. subtilis & S.aureus \\
\hline & & (-ve) & (-ve) & (+ve) & (+ve) \\
\hline \multirow[t]{5}{*}{ Ethyl acetate } & 100 & 16 & 19 & 22 & 21 \\
\hline & 50 & 15 & 18 & 19 & 20 \\
\hline & 25 & 14 & 17 & 19 & 19 \\
\hline & 12.5 & 12 & 15 & 17 & 17 \\
\hline & amoxicillin & 24 & 36 & 36 & 34 \\
\hline
\end{tabular}

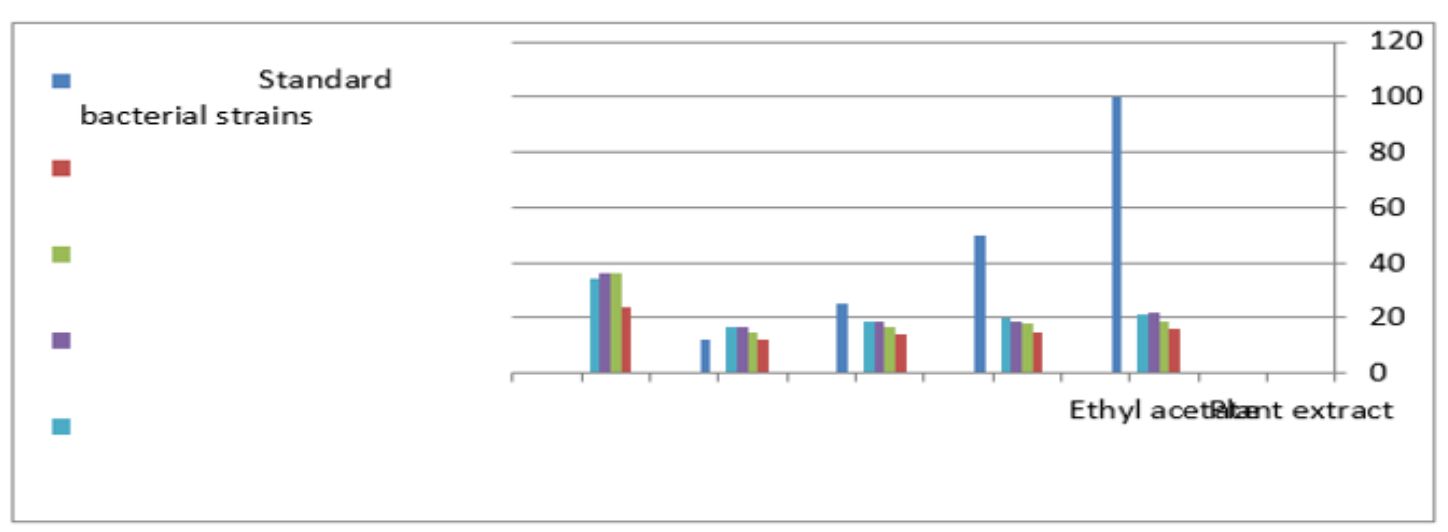

\section{Antioxidant}

Propyl gallate was used as standard and showed the result of $(31 \pm 0.03)$ in Table 2 after running of triplicate process. That means Ziziphus spina Christihas an antioxidant activity through the comparison with dimethyl sulfoxide (DMSO) which considered as oregano sulfur compound. This colorless liquid is an important polar aprotic solvent that dissolves both polar and non-polar compounds and is miscible in wide range of organic solvents as well as water. It has a relatively high boiling point [8].

Table 2: The antioxidant activity of Ziziphus spina Christi extract against standard propyl gallate.

\begin{tabular}{|c|c|}
\hline No. & \% RSA \pm SD \\
\hline (DPPH) & $61 \pm 0.04$ \\
\hline Standard (Propyl gallate) & $93 \pm 0.01$ \\
\hline
\end{tabular}

Also, propyl gallate exhibits antimicrobial activity and has reported to an effective antioxidant based hepatoprotector. Finally, this reagent used as anti-fade in fluorescence microscopy to reduce photobleaching of fluorescent probes such as rhodamine and fluorescein [1]. A balance between free radical and antioxidant is necessary for proper physiological function. If free radical overwhelms the body's ability to regulate them a condition known as oxidative stress ensues. Application of external source of antioxidants can assist in coping oxidative stress [9-11].

\section{Conclusion}

\section{Anti-microbial}

- Anti-biotics had the ability to inhibit the growth of bacteria; therefore, we must detect the suitable one for treatment Table 1.

- Anti-bacterial activity differs with applied extractive method.
- Anti-bacterial activities support further studies to discover the new chemical structures that can contribute to alleviate or cure some illnesses.

\section{Antioxidant}

- Antioxidants counteract by products called free radical.

- Antioxidant may possible the development of cancer.

- Some food sources of antioxidant such as Beta-Carotene, vitamin (A), (C) and (E) must be available within the meals.

\section{Acknowledgement}

- Great thanks for natural research center for their cooperation.

- Deep greetings to the Department of Biology and Technology - Faculty of Applied science and Technology and Industry - University of Bahri. 


\section{References}

1. Shimada K, Fujikawa K, Yahara K, Nakamura T (1992) Antioxidative properties of xanthan on the anti-oxidation of soya bean oil in cyclodextrin emulsion 40: 945-948.

2. Wain W (1989) Mould in ancient and more recent medicine 3(1): 21-23.

3. Kingston $W$ (2008) Irish contributions to the origins of antibiotics 177(2): 87-92.

4. Jiang L, Pearson, Crews ST (2010) Diverse mode of Drosophilla tracheal fusion cell transcriptional regulation 127(5-6): 265-280.

5. Stanner SA, Hughes J, Kelly CNM, J Buttriss (2004) A review of epidemiological evidence for the antioxidant hypothesis 7(3): 22-407.
6. Sabath MD (1976) The assay of antimicrobial compounds 7(3): 287-295.

7. Mounyr B, Moulay S, Saad KI (2016) Methods for in vitro evaluating antimicrobial activity 6(2): 71-79.

8. Smith ER, Hadidian Z, Mason MM (1967) Dose toxicity of dimethyl sulfoxide 141(1): 96-109.

9. Lobo V, Patel A, Phalak A, Chandra N (2010) Free radicals, antioxidants, and functional foods: Impact in human health 4(8): 118-126.

10. Miles AA, Misra SS (1938) The estimation of bactericidal power of the blood 38(6): 732-749.

11. Fleming A (1929) On the antibacterial reaction of cultures of a pencillium with special reference to their use in isolation of B. influenza 10(3): 226236.

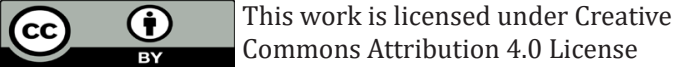

To Submit Your Article Click Here: Submit Article

DOI: $10.32474 /$ OAJESS.2020.05.000204

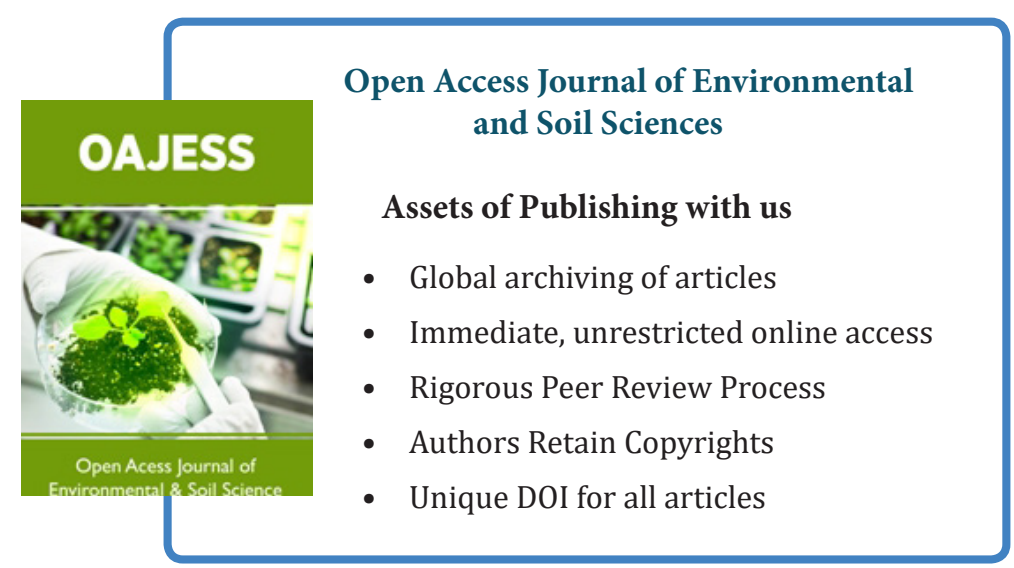

